East European Journal of Physics

East Eur. J. Phys. 1. 55-64 (2019)

DOI:10.26565/2312-4334-2019-1-05

PACS: $03.65 . P m$

\title{
DYNAMICS OF ELECTRON IN TEM WAVE FIELD
}

\author{
(D)Yuriy Grigoriev', (D)Andrey Zelinskiy ${ }^{1}$, (D)Tetiana Malykhina ${ }^{2}$, \\ (D)Valentina Shpagina ${ }^{1 *}$ \\ 'National Science Center "Kharkiv Institute of Physics and Technology" \\ ${ }^{I}$ Akademichna str., 61108, Kharkiv, Ukraine \\ ${ }^{2}$ Kharkiv V.N. Karazin National University \\ 4, Svobody sq., 61022, Kharkiv, Ukraine \\ *E-mail:valentinash0607@gmail.com \\ Received December 21, 2018; revised January 29, 2019; accepted March 15, 2019
}

Big amount of works deals with solution of differential equations, associated with electron motion in electromagnetic field, using methods of classical electrodynamics. Solution of equation of an electron motion in TEM wave field is interesting task because this equation is mathematical model of big number of wave processes, which are used for researches of different physical processes. The proposed work dedicated to finding the solution for the equation of an electron motion in TEM wave field in laboratory system of coordinates using the theory of almost periodic functions. The work demonstrates that the projections of electron velocity on coordinate axis conform to the wave equation, and, consequently, could be expanded into generalized Fourier series at any value of the wave and electron parameters. In the present work, the formulas received before for electron velocity projection on coordinate axis, are transformed to a well-behaved form, and are broken down into non-perfect generalized Fourier series. Non-perfect Fourier series for projections of electron velocity on coordinate axis are found by means of plotting of complex series, which are called in the theory of almost periodic functions as "closure of set". For approximate computation of electron velocity it is possible to restrict oneself to finite number of series harmonics. Application of method of electron velocity components transformation into generalized Fourier series made it possible to find in electron velocity components series terms, which do not depend on time and are equal to average magnitudes of the respective values. Electron velocity components present functions of initial magnitudes of electron velocity components, of generalized phase magnitude and of the wave parameters. Initial magnitudes are not preset at random, but calculated from the equations, the type of which is specified in the work. Electron trajectory in coordinate space is calculated by integrating of the respective expressions for velocity projections on coordinate axis. For demonstration purpose the work deals with the example of electron dynamics in wave polarization plane with consideration of only permanent addends and first harmonics of Fourier series for electron velocity projections on coordinate axis. An approximate solution of the equations of electron dynamics in the plane of polarization of the wave is given. Solution for the equation of electron motion in TEM wave field in the laboratory coordinate system using the theory of almost periodic functions made it possible to solve the problem of dynamics of relativistic electron in the field of progressing TEM wave. It made it possible to demonstrate the availability of time-independent summands in the value of the speed of the electron, which moves in TEM wave. A very important circumstance is also the fact, that the theory makes it possible to investigate electron dynamics depending on the original wave intensity.

KEYWORDS: wave equation, generalized Fourier series, TEM wave.

ДИНАМІКА ЕЛЕКТРОНУ В ПОЛІ ТЕМ ХВИЛІ

Ю.М. Григор'св ${ }^{1}$, А.Ю. Зелінський ${ }^{1}$, Т.В. Малихіна ${ }^{2}$, В.О. Шпагіна ${ }^{1}$

${ }^{1}$ Національний науковий центр Харківський фізико-технічний інститут вул. Академічна, 1, 61108, Харків, Украӥна

${ }^{2}$ Харківський національний університет імені В.Н. Каразіна майдан Свободи, 4, 61022, Харків, Украӥна

Розв'язанню диференційних рівнянь руху електрона в електромагнітному полі методами класичної електродинаміки присвячено велику кількість робіт. Розв'язання рівняння руху електрону у полі ТЕМ хвилі є важливою науковою задачею у зв'язку з тим, що це рівняння $є$ математичною моделлю великої кількості хвильових процесів, котрі виникають під час досліджень різноманітних фізичних явищ. Пропонована робота присвячена отриманню розв'язанню рівняння руху електрона у полі ТЕМ хвилі в лабораторній системі координат, із використанням теорії майже періодичних функцій. В роботі показано, що проекції швидкості електрона на вісі координат відповідають хвильовому рівнянню, і отже, можуть бути розкладені в узагальнені ряди Фур'є при будь-яких значеннях параметрів хвилі електрона. У роботі вирази для проекцій швидкості електрону на вісі координат приведені до вигляду, зручному для аналізу, й розкладаються у реальні узагальнені ряди Фур'є. Реальні ряди Фур'є для проекцій швидкості електрону на вісі координат обчислюються за допомогою побудови комплексних рядів, що називаються у теорії майже періодичних функцій “замкненням множини”. Для наближеного обчислення швидкості електрона можна обмежитися кінцевим числом гармонік ряду. Застосування методу розкладання компонент швидкості електрона в узагальнені ряди Фур'є дало можливість виявити у компонентах швидкості електрона члени ряду, які не залежать від часу, що дорівнюють середнім значенням відповідних величин. Компоненти швидкості електрона $є$ функціями часу, початкових значень компонент швидкості електрона, початкового значення узагальненої фази, і параметрів хвилі. Початкові значення компонент швидкості електрона не задаються довільно, а обчислюються з рівнянь, вид яких наводиться у даній роботі. Траєкторія електрона в координатному просторі обчислюється інтегруванням відповідних виразів для проекцій швидкості на вісі координат. В роботі розглянуто приклад динаміки електрона у площині поляризації хвилі з урахуванням тільки постійних доданків і перших гармонік рядів Фур'є для проекцій швидкості електрона на вісі координат. Наведене наближене розв'язання рівнянь динаміки електрона у площині 
поляризації хвилі, що надало можливість отримати формули швидкості електрона у вигляді явних функцій часу. Отримані формули можуть бути використані для дослідження динаміки електрона у полі ТЕМ хвилі як малої, так i великої інтенсивності.

КЛЮЧОВІ СЛОВА: хвильове рівняння, узагальнені ряди Фур’є, ТЕМ хвиля

ДИНАМИКА ЭЛЕКТРОНА В ПОЛЕ ТЕМ ВОЛНЫ

Ю.Н. Григорьев ${ }^{1}$, А.Ю. Зелинский ${ }^{1}$, Т.В. Малыхина ${ }^{2}$, В.О. Шпагина ${ }^{1}$

${ }^{1}$ Национальный научный центр Харьковский физико-технический институт ул. Академическая, 1, 61108, Харьков, Украина

${ }^{2}$ Харьковский национальный университет имени В.Н. Каразина майдан Свободы, 4, 61022, Харьков, Украина

Решению дифференциальных уравнений движения электрона в электромагнитном поле методами классической электродинамики посвящено большое число работ. Решение уравнения движения электрона в поле ТЕМ волны представляет интерес в связи с тем, что это уравнение является математической моделью большого числа волновых процессов, которые встречаются при исследовании различных физических явлений. Предлагаемая работа посвящена получению решения уравнения движения электрона в поле ТЕМ волны в лабораторной системе координат с использованием теории почти периодических функций. В работе показано, что проекции скорости электрона на оси координат удовлетворяют волновому уравнению, и, следовательно, могут быть разложены в обобщённые ряды Фурье при любых значениях параметров волны и электрона. В данной работе выражения для проекций скорости электрона на оси координат приведены к виду, удобному для анализа, и раскладываются в реальные обобщённые ряды Фурье. Реальные ряды Фурье для проекций скорости электрона на оси координат находятся с помощью построения комплексных рядов, называемых в теории почти периодических функций “замыканием множества". Для приближённого вычисления скорости электрона можно ограничиться конечным числом гармоник ряда. Применение метода разложения компонент скорости электрона в обобщённые ряды Фурье дало возможность обнаружить в компонентах скорости электрона члены ряда, не зависящие от времени, равные средним значениям соответствующих величин. Компоненты скорости электрона являются функциями времени, начальных значений компонент скорости электрона, начального значения обобщённой фазы, и параметров волны. Начальные значения компонент скорости электрона не задаются произвольно, а вычисляются из уравнений, вид которых приводится в данной работе. Траектория электрона в координатном пространстве вычисляется интегрированием соответствующих выражений для проекций скорости на оси координат. Для иллюстрации в работе рассмотрен пример динамики электрона в плоскости поляризации волны с учётом только постоянных слагаемых и первых гармоник рядов Фурье для проекций скорости электрона на оси координат. Приведено приближенное решение уравнений динамики электрона в плоскости поляризации волны. Решение уравнения движения электрона в поле ТЕМ волны в лабораторной системе координат с использованием теории почти периодических функций дало возможность получить формулы скорости электрона в виде явных функций времени. Полученные формулы могут быть использованы для исследования динамики электрона в поле ТЕМ волны как малой, так и большой интенсивности.

КЛЮЧЕВЫЕ СЛОВА: волновое уравнение, обобщённые ряды Фурье, ТЕМ волна.

Big amount of works deals with solution of differential equations, associated with electron motion in electromagnetic field, using methods of classical electrodynamics.

Solution of equation of an electron motion in TEM wave field is interesting task because this equation is mathematical model of big number of wave processes, which are used for researches of different physical processes. For example, mechanical fluctuations in elastic strings, fluctuations in radio engineering devices, quartz crystal and etc. Thereby tasks, which can be described by wave equation and also solution of equation of an electron motion in TEM wave field, are actual.

The goal of this work is solving the equation of electron motion in the field of TEM wave using the theory of almost periodic functions in order to obtain exact formulas for electron coordinates and velocities in the form of explicit functions of time.

The usage of almost periodic functions theory gives an opportunity to get precise formulas of electron coordinates and velocity in a form of explicit functions of time. The received formulas are suitable for analysis of electron dynamics in the fields of both low and high field intensity.

In the work [1] the formulas are given for electron velocity projections on coordinate axis in TEM wave field, which are the functions of the wave generalized phase, and were received as a result of integration of dynamics differential equation. In the present work, the formulas received before for electron velocity projection on coordinate axis, are transformed to a well-behaved form, and are broken down into non-perfect generalized Fourier series. Nonperfect Fourier series for projections of electron velocity on coordinate axis are found by means of plotting of complex series, which are called in the theory of almost periodic functions as "closure of set" [2].

Application of method of electron velocity components transformation into generalized Fourier series made it possible to find in electron velocity components series terms, which do not depend on time and are equal to average magnitudes of the respective values.

Electron velocity components present functions of initial magnitudes of electron velocity components, of generalized phase magnitude and of the wave parameters. Initial magnitudes are not preset at random, but calculated from the equations, the type of which is specified in the work.

Electron trajectory in coordinate space is calculated by integrating of the respective expressions for velocity projections on coordinate axes. 


\section{INTEGRATING OF DIFFERENTIAL EQUATION OF ELECTRON MOTION IN WAVE FIELD}

Differential equation of electron motion [3] in electromagnetic field has the following form

$$
\frac{d}{d t}\left(\frac{m \vec{v}}{\sqrt{1-\beta^{2}}}\right)=e \vec{E}+\frac{e}{c}[\vec{v} \times \vec{M}]
$$

where $m$ is electron mass and $e$ is electron charge, $c$ is the velocity of light, $t$ is time, $\vec{v}=\frac{d \vec{r}}{d t}$,

$\vec{r}=\vec{i} x+\vec{k} z+\vec{j} y, \vec{r}$ is electron radius-vector, $\vec{E}, \vec{M}$ - electric and magnetic field vector, respectively, $\beta=\frac{v}{c}$.

Let us present electric component of the field in the following form

$$
E_{z}=E \cos \left[2 \pi v\left(t-\frac{x(t)}{c}\right)+\delta\right]
$$

where $v$ is frequency, $\delta$ is phase of the wave at $t_{0}=0$ and $x\left(t_{0}\right)=0, t_{0}$ is initial time, $E_{z}$ is projection of the wave electric component: $E_{x}=0, E_{y}=0$. We will assume, that progressive wave normal has the direction, which coincides with the direction of $x$ axis. Vector of magnetic field has the following form

$$
\vec{M}=[\vec{i} \vec{E}]
$$

Having projected (1) on coordinate axes, we will get:

$$
\begin{aligned}
& \frac{1}{c} \frac{d}{d t}\left(W \beta_{z t}\right)=W\left(1-\beta_{x t}\right) E \cos \left[2 \pi v\left(t-\frac{x(t)}{c}\right)+\delta\right] \\
& \frac{1}{c} \frac{d}{d t}\left(W \beta_{x t}\right)=W \beta_{z t} E \cos \left[2 \pi v\left(t-\frac{x(t)}{c}\right)+\delta\right] \\
& \frac{1}{c} \frac{d}{d t}\left(W \beta_{y t}\right)=0
\end{aligned}
$$

where $W$ is electron energy, $\beta_{x t}=\frac{1}{c} \frac{d x}{d t}, \beta_{y t}=\frac{1}{c} \frac{d y}{d t}, \beta_{z t}=\frac{1}{c} \frac{d z}{d t}$

Each of the equations (4-6) could be integrated one time. When taking integral of equation (4) the formula for energy change was used:

$$
\frac{d W}{d t}=W \frac{d z}{d t} E \cos \left[2 \pi v\left(t-\frac{x(t)}{c}\right)+\delta\right]
$$

Integrating (4-6), and solving the received expressions with respect to $\beta_{x t}, \beta_{z t}, \beta_{y t}$, we will get:

$$
\begin{aligned}
& \beta_{x t}=\frac{1+F^{2}+a^{2}-B^{2}}{1+F^{2}+a^{2}+B^{2}} \\
& \beta_{z t}=\frac{2 B F}{1+F^{2}+a^{2}+B^{2}} \\
& \beta_{y t}=\frac{2 a B}{1+F^{2}+a^{2}+B^{2}}
\end{aligned}
$$

where

$$
\begin{gathered}
a=\frac{\beta_{y t}\left(t_{0}\right)}{1-\beta_{x t}\left(t_{0}\right)} \\
F=\frac{W E}{m c(2 \pi v)} \sin \left[2 \pi v\left(t-\frac{x(t)}{c}\right)+\delta\right]+C \\
C=\frac{\beta_{z t}\left(t_{0}\right)}{\sqrt{1-\beta\left(t_{0}\right)^{2}}}-\frac{W E}{m c(2 \pi v)} \sin \left[2 \pi v\left(t_{o}-\frac{x\left(t_{o}\right)}{c}\right)+\delta\right] \\
B=\frac{1-\beta_{x t}(t)}{\sqrt{1-\beta^{2}(t)}}=\frac{1-\beta_{x t}\left(t_{0}\right)}{\sqrt{1-\beta^{2}\left(t_{0}\right)}}
\end{gathered}
$$



phase:

One can see from (13), that value $B$ is motion integral. To integrate equations (7-9), let us introduce generalized

$$
s=t-\frac{x(t)}{c}
$$

Differentiating (13) with respect to $t$ and, introducing the following symbols:

$$
\frac{1}{c} \frac{d x}{d s}=\beta_{x s}, \frac{1}{c} \frac{d z}{d s}=\beta_{z s}, \frac{1}{c} \frac{d y}{d s}=\beta_{y s}
$$

we will get:

$$
\beta_{x t}=\frac{\beta_{x s}}{1+\beta_{x s}}, \beta_{z t}=\frac{\beta_{z s}}{1+\beta_{x s}}, \beta_{y t}=\frac{\beta_{y s}}{1+\beta_{x s}}
$$

Inserting (14) in (7-9) and, solving the received expressions with respect to $\beta_{x s}, \beta_{z s}, \beta_{y s}$, as well as using (10-13), we get:

$$
\begin{aligned}
& \beta_{y s}=\Lambda_{y}=\frac{\beta_{y t}\left(t_{0}\right)}{1-\beta_{x t}\left(t_{0}\right)} \\
& \beta_{z s}=p \sin [2 \pi v s+\delta]+\Lambda_{z} \\
& \beta_{x s}=-\frac{p^{2}}{4} \cos [2(2 \pi v s+\delta)]+p \Lambda_{z} \sin [2 \pi v s+\delta]+\Lambda_{x}
\end{aligned}
$$

where

$$
\begin{aligned}
& p=\frac{W E}{m c(2 \pi v) B} \\
& \Lambda_{z}=\frac{\beta_{z t}\left(t_{0}\right)}{1-\beta_{x t}\left(t_{0}\right)}-p \sin \left[2 \pi v s_{0}+\delta\right] \\
& \Lambda_{x}=\frac{\beta_{x t}\left(t_{0}\right)}{1-\beta_{x t}\left(t_{0}\right)}+\frac{1}{4} p^{2} \cos \left[2\left(2 \pi v s_{0}+\delta\right)\right]-p \Lambda_{z} \sin \left[2 \pi v s_{0}+\delta\right]
\end{aligned}
$$

Integrating (16-18), we get

$$
\begin{aligned}
& \frac{1}{c} y(s)=\Lambda_{y} s+b_{y} \\
& \frac{1}{c} z(s)=\psi_{z}(s)+\Lambda_{z} s+b_{z} \\
& \frac{1}{c} x(s)=\varphi(s)+\Lambda_{x} s+b_{x}
\end{aligned}
$$

where

$$
\begin{aligned}
& \psi_{z}(s)=-\frac{p}{2 \pi \nu} \cos [2 \pi v s+\delta] \\
& \varphi(s)=-\frac{p^{2}}{8(2 \pi v)} \sin [2(2 \pi v s+\delta)]-\frac{p \Lambda_{z}}{(2 \pi v)} \sin [2 \pi v s+\delta] \\
& b_{y}=\frac{1}{c} y\left(s_{0}\right)-\Lambda_{y} s_{0} \\
& b_{z}=\frac{1}{c} z\left(s_{0}\right)+\frac{p}{2 \pi v} \cos \left[2 \pi v s_{0}+\delta\right]-\Lambda_{z} s_{0} \\
& b_{x}=\frac{1}{c} x\left(s_{0}\right)+\frac{p^{2}}{8(2 \pi v)} \sin \left[2\left(2 \pi v s_{0}+\delta\right)\right]+\frac{p \Lambda_{z}}{(2 \pi v)} \sin \left[2 \pi v s_{0}+\delta\right]-\Lambda_{x} s_{0}
\end{aligned}
$$




\section{EXPANDING OF THE PROJECTIONS OF ELECTRON VELOCITY ON COORDINATE AXES INTO} GENERALIZED FOURIER SERIES

From formulas (7-9) it follows, that $\beta_{x t}, \beta_{z t}, \beta_{y t}$ are the functions of generalized phase $s$. That is why in compliance with [4], $\beta_{x t}, \beta_{z t}, \beta_{y t}$ satisfy wave equation.

In accordance with [5] the functions, satisfying wave equation, are almost periodic ones and consequently they can be expanded into generalized Fourier series.

In compliance with [2] let us present $\beta_{x t}$ in terms of series:

$$
\beta_{x t}=c_{x}+\sum_{n=-\infty}^{n=-1} c_{n} e^{i \Omega_{n} t}+\sum_{n=1}^{n=\infty} c_{n} e^{i \Omega_{n} t}
$$

where

$$
c_{x}=\lim _{T \rightarrow \infty}\left[\frac{1}{T} \int_{t_{o}}^{t_{o}+T} \beta_{x t} d t\right]
$$

In (31) let us shift from integrating with respect to $t$ to integrating with respect to $S$.

Differentiating (13) with respect to $t$, we get:

$$
\frac{d s}{d t}=1-\beta_{x t}
$$

Inserting $\beta_{x t}$ in (32) from (7), we will get:

$$
d t=\frac{d s}{2 B^{2}}\left(1+F^{2}+a^{2}+B^{2}\right)
$$

Inserting $d t$ in (31), we will get:

$$
c_{x}=\lim _{S \rightarrow \infty}\left[\frac{1}{S} \int_{s_{o}}^{s_{o}+S} \frac{1}{2 B^{2}}\left(1+F^{2}+a^{2}-B^{2}\right) d s\right]
$$

Inserting $F$ from (11) in (34), we will get:

$$
c_{x}=\frac{1}{2 B^{2}}\left(1+\frac{H^{2}}{2}+C^{2}+a^{2}-B^{2}\right)
$$

where

$$
H=\frac{W E}{m c(2 \pi v)}
$$

$c_{x}-$ is mean value of $\beta_{x t}$, which is calculated at $\Omega_{n}=0$. It corresponds to $n=0$.

Harmonic amplitude is determined by expression:

$$
c_{n}=\lim _{T \rightarrow \infty}\left[\frac{1}{T} \int_{t_{0}}^{t_{0}+T} \beta_{x t} e^{-i \Omega_{n}} d t\right]
$$

In (37) let us pass from $t$ to $s$.

$$
c_{n}=\lim _{S \rightarrow \infty}\left[\frac{1}{S} \int_{s_{o}}^{s_{o}+S} \frac{1}{2 B^{2}}\left(1+F^{2}+a^{2}-B^{2}\right) e^{-i \Omega_{n}\left(s+\frac{x(s)}{c}\right)} d s\right]
$$

Instead of $\frac{x(s)}{c}$ and using (24), we insert expression

$$
\frac{1}{c} x(s)=\varphi(s)+\Lambda_{x} s+b_{x}
$$

Without breaking generality essentially, we will here after assume $\delta=0$.

Let us expand element of integration for $c_{n}$. 


$$
\begin{aligned}
& c_{n}=e^{-i \Omega_{n} b_{x}} \lim _{S \rightarrow \infty}\left[\frac{1}{S} \int_{s_{o}}^{s_{o}+S} \frac{d s}{2 B^{2}}\left(1+H^{2} \sin ^{2}[2 \pi \nu s]+2 H C \sin [2 \pi \nu s]+C^{2}+a^{2}-B^{2}\right)\right] \times \\
& \times e^{-i \Omega_{n}\left(\Lambda_{x}+1\right) s} \times e^{-i \Omega_{n} \varphi(s)}
\end{aligned}
$$

We will preset frequency $\Omega_{n}$ in the following way:

$$
\Omega_{n}=\frac{2 \pi v n}{\Lambda_{x}+1}(n=\ldots 3,2,1,-1,-2-3)
$$

Value $e^{-i \Omega_{n} \varphi(s)}$ will be reported in terms:

$$
e^{-i \Omega_{n} \varphi(s)}=\cos \left[\Omega_{n} \varphi(s)\right]-i \sin \left[\Omega_{n} \varphi(s)\right],
$$

and

$c_{n}=c_{n}^{c}-i c_{n}^{s}$, where

$$
\begin{aligned}
& c_{n}^{c}=e^{-i \Omega_{n} b_{x}} \lim _{S \rightarrow \infty}\left[\frac{1}{S} \int_{s_{o}}^{s_{o}+s} \frac{d s}{2 B^{2}}\left(1+H^{2} \sin ^{2}[2 \pi v s]+2 H C \sin [2 \pi v s]+C^{2}+a^{2}-B^{2}\right)\right] \times \\
& \times e^{-i 2 \pi v n s} \cos \left[\Omega_{n} \varphi(s)\right] \\
& c_{n}^{s}=e^{-i \Omega_{n} b_{x}} \lim _{S \rightarrow \infty}\left[\frac{1}{S} \int_{s_{o}}^{s_{o}+S} \frac{d s}{2 B^{2}}\left(1+H^{2} \sin ^{2}[2 \pi v s]+2 H C \sin [2 \pi v s]+C^{2}+a^{2}-B^{2}\right)\right] \times \\
& \times e^{-i 2 \pi v v s s} \sin \left[\Omega_{n} \varphi(s)\right]
\end{aligned}
$$

Non-perfect generalized Fourier series for electron velocity projections on coordinate axis are found by means of plotting of complex series, which in the theory of almost periodic functions are called "closure of set" [2].

Having designated

$$
\left(\sum_{n=1}^{n=\infty} c_{n}^{c} e^{i 2 \pi v n t}+\sum_{n=-1}^{n=-\infty} c_{n}^{c} e^{i 2 \pi v n t}\right)=F^{c} ;\left(\sum_{n=1}^{n=\infty} c_{n}^{s} e^{i 2 \pi v n t}+\sum_{n=-1}^{n=-\infty} c_{n}^{s} e^{i 2 \pi v n t}\right)=F^{s}
$$

and, using the above formulas, $\beta_{x t}$ could be reported in terms of:

$$
\begin{aligned}
& \beta_{x t}=\frac{1}{2 B^{2}}\left(1+\frac{H^{2}}{2}+C^{2}+a^{2}-B^{2}\right)+F^{c}-i F^{s} \\
& \beta_{x t}^{*}=\frac{1}{2 B^{2}}\left(1+\frac{H^{2}}{2}+C^{2}+a^{2}-B^{2}\right)+\left(F^{c}\right)^{*}+i\left(F^{s}\right)^{*}
\end{aligned}
$$

$\beta_{x t}-$ complex function, $\beta_{x t}^{*}$ is a complex conjugate of function $\beta_{x t}$

$$
\left(\beta_{x t}+\beta_{x t}^{*}\right)=\frac{1}{B^{2}}\left(1+\frac{H^{2}}{2}+C^{2}+a^{2}-B^{2}\right)+\left(\left(F^{c}+\left(F^{c}\right)^{*}\right)-i F^{s}+i\left(F^{s}\right)^{*}\right) .
$$

Function $\beta_{x t}^{p}=\beta_{x t}+\beta_{x t}^{*}$ is a valid (attached) solution.

Let us expand valid solution of $\beta_{x t}$ (attached):

Let us expand

$$
\beta_{x t}^{p}=\beta_{x t}+\beta_{x t}^{*} .
$$

$$
c_{n}^{c} e^{-i \Omega_{n} b_{x}} e^{\frac{i 2 \pi v n t}{1+\Lambda_{x}}}=c_{n}^{c} e^{\frac{i 2 \pi v n\left(t-b_{x}\right)}{1+\Lambda_{x}}} ;
$$

let us designate $c_{n}^{c}=q_{n}+i r_{n}$ and $c^{s}=\xi_{n}+i \eta_{n}$; it is possible to demonstrate that, $c_{-n}^{c}=q_{n}-i r$ and $c_{-n}^{s}=\xi_{n}-i \eta_{n}$, then:

$$
F^{c}=\left(F^{c}\right)^{*} \text { and } F^{s}=\left(F^{s}\right)^{*}
$$

and then in compliance with (46)

$$
\beta_{x t}^{p}=\frac{1}{B^{2}}\left(1+\frac{H^{2}}{2}+C^{2}+a^{2}-B^{2}\right)+2 \sum_{n=1}^{n=\infty}\left(q_{n} \cos \left[\Omega_{n}\left(t-b_{x}\right)\right]-r_{n} \sin \left[\Omega_{n}\left(t-b_{x}\right)\right]\right)
$$


We will specify formulas for calculation of $q_{n}, r_{n}$. And for this purpose use formula (42)

$$
\begin{aligned}
& q_{n}+i r_{n}=\lim _{S \rightarrow \infty}\left[\frac{1}{S} \int_{s_{o}}^{s_{o}+S} \frac{d s}{2 B^{2}}\left(1+H^{2} \sin ^{2}[2 \pi v s]+2 H C \sin [2 \pi v s]+C^{2}+a^{2}-B^{2}\right)\right] \times \\
& \times e^{-i 2 \pi v n s} \cos \left[\Omega_{n} \varphi(s)\right]
\end{aligned}
$$

It is possible to expand $\cos \left[\Omega_{n} \varphi(s)\right]$ into infinite series at any values of its argument. From here it follows, that by means of formula (49) longitudinal electron velocity projection could be calculated with any degree of precision.

Using the formulas specified above, we can present real attached solution for $\beta_{x t}$ in a form of series:

$$
\beta_{x t}=2 c_{x}+2 \sum_{n=1}^{n=\infty}\left(q_{n} \cos \left[\frac{2 \pi v n\left(t-b_{x}\right)}{1+\Lambda_{x}}\right]-r_{n} \sin \left[\frac{2 \pi v n\left(t-b_{x}\right)}{1+\Lambda_{x}}\right]\right)
$$

Here comes the attached solution for $\beta_{z t}$ :

$$
\beta_{z t}=2 c_{z}+2 \sum_{n=1}^{n=\infty}\left(Q_{n} \cos \left[\frac{2 \pi v n\left(t-b_{x}\right)}{1+\Lambda_{x}}\right]-R_{n} \sin \left[\frac{2 \pi v n\left(t-b_{x}\right)}{1+\Lambda_{x}}\right]\right)
$$

where

$$
\begin{aligned}
& c_{z}=\frac{1}{B} \lim _{S \rightarrow \infty}\left[\frac{1}{S} \int_{s_{o}}^{s_{o}+S} F(s) d s\right]=\frac{C}{B} \\
& Q_{n}+i R_{n}=\lim _{S \rightarrow \infty}\left[\frac{1}{S} \int_{s_{o}}^{s_{o}+S} \frac{d s}{2 B^{2}} 2 B F(s) e^{-i 2 \pi v n s}\left(1+\sum_{n=1}^{n=\infty} \frac{\left(\Omega_{n} \varphi(s)\right)^{2 n}}{(2 n) !}\right)\right]
\end{aligned}
$$

Analogically, the attached solution is done for $\beta_{y t}$.

$$
\begin{gathered}
\beta_{y t}=2 c_{y}+2 \sum_{n=1}^{n=\infty}\left(\xi_{n} \cos \left[\frac{2 \pi v n\left(t-b_{x}\right)}{1+\Lambda_{x}}\right]-\eta_{n} \sin \left[\frac{2 \pi v n\left(t-b_{x}\right)}{1+\Lambda_{x}}\right]\right) \\
c_{y}=\frac{a}{B} \\
\xi_{n}+i \eta_{n}=\lim _{S \rightarrow \infty}\left[\frac{1}{S} \int_{s_{o}}^{s_{o}+S} \frac{d S}{2 B^{2}} 2 B a e^{-i 2 \pi v n s}\left(1+\sum_{n=1}^{n=\infty} \frac{\left(\Omega_{n} \varphi(s)\right)^{2 n}}{(2 n) !}\right)\right]
\end{gathered}
$$

The position of electron in coordinate space could be calculated by means of the formulas, received as a result of integrating of (51), (52), (55).

$$
\begin{aligned}
& \frac{1}{c} x=2 c_{x} t+2 \sum_{n=1}^{n=\infty} \frac{1}{\Omega_{n}}\left(q_{n} \sin \left[\Omega_{n}\left(t-b_{x}\right)\right]+r_{n} \cos \left[\Omega_{n}\left(t-b_{x}\right)\right]\right), \\
& \frac{1}{c} z=2 c_{z} t+2 \sum_{n=1}^{n=\infty} \frac{1}{\Omega_{n}}\left(q_{n} \sin \left[\Omega_{n}\left(t-b_{x}\right)\right]+R_{n} \cos \left[\Omega_{n}\left(t-b_{x}\right)\right]\right), \\
& \left.\frac{1}{c} y=2 c_{y} t+2 \sum_{n=1}^{n=\infty} \frac{1}{\Omega_{n}}\left(\xi_{n} \sin \left[\Omega_{n}\left(t-b_{x}\right)\right]\right]+\eta_{n} \cos \left[\Omega_{n}\left(t-b_{x}\right)\right]\right) .
\end{aligned}
$$

For further transformations and calculations let us introduce the following designations: $2 \pi v\left(t-b_{x}\right)$;

$$
t=t_{0}+\tau ; \Phi=2 \pi v \tau+\Phi_{0} ; 2 \pi v s_{0}=g_{0},
$$

The expression for $\Phi_{0}$ could be transformed into the following form:

$$
\Phi_{0}=\left(1+\Lambda_{x}\right) g_{0}-\frac{H^{2}}{8 B^{2}} \sin \left[2 g_{0}\right]-\frac{H}{B} \Lambda_{z} \sin \left[g_{0}\right]-\delta\left(1+\Lambda_{x}\right)+\frac{2 \pi v}{c}\left(x\left(t_{0}\right)-x\left(s_{0}\right)\right) .
$$

It is possible to demonstrate that $x\left(t_{0}\right)-x\left(s_{0}\right)=0$. 
To calculate the values $\beta_{x}\left(t_{0}\right), \beta_{z}\left(t_{0}\right), x\left(t_{0}\right)$, to it is necessary in equations (51), (52) to set value $t=t_{0}$. We will get three equations:

$$
\begin{gathered}
2 c_{x}+2 \sum_{n=1}^{n=\infty}\left(q_{n} \cos \frac{2 \pi v n \Phi_{0}}{1+\Lambda_{x}}-r_{n} \sin \frac{2 \pi v n \Phi_{0}}{1+\Lambda_{x}}\right)-\beta_{x}\left(t_{0}\right)=0 \\
2 c_{z}+2 \sum_{n=1}^{n=\infty}\left(Q_{n} \cos \frac{2 \pi v n \Phi_{0}}{1+\Lambda_{x}}-R_{n} \sin \frac{2 \pi v n \Phi_{0}}{1+\Lambda_{x}}\right)-\beta_{z}\left(t_{0}\right)=0 \\
\frac{1}{c} x\left(t_{0}\right)=2 c_{x} t_{0}+2 \sum_{n=1}^{n=\infty} \frac{1}{\Omega_{n}}\left(q_{n} \sin \frac{2 \pi v n \Phi_{0}}{1+\Lambda_{x}}+r_{n} \cos \frac{2 \pi v n \Phi_{0}}{1+\Lambda_{x}}\right)
\end{gathered}
$$

The following equation should be added to equations (62) - (64):

$$
g_{0}=2 \pi v\left(t_{0}-\frac{x\left(t_{0}\right)}{c}\right)
$$

First we find $\beta_{x}\left(t_{0}\right), \beta_{z}\left(t_{0}\right)$, which satisfy equations (62), (63).

Then, using equations (64) and (65) we find:

$$
\begin{aligned}
& \frac{x\left(t_{0}\right)}{c}=\frac{2 \pi v Y+2 c_{x} g_{0}}{2 \pi v\left(1-2 c_{x}\right)} \\
& t_{0}=\frac{g_{0}+2 \pi v Y}{2 \pi v\left(1-2 c_{x}\right)}
\end{aligned}
$$

where

$$
Y=2 \sum_{n=1}^{n=\infty} \frac{1}{\Omega_{n}}\left(q_{n} \sin \frac{2 \pi v n \Phi_{0}}{1+\Lambda_{x}}+r_{n} \cos \frac{2 \pi v n \Phi_{0}}{1+\Lambda_{x}}\right)
$$

Left parts of equations (61), (62) depend on $g_{0}, \beta_{x}\left(t_{0}\right), \beta_{z}\left(t_{0}\right), H$.

Thus, $\beta_{x}\left(t_{0}\right)$ and $\beta_{z}\left(t_{0}\right)$ should be the solutions of equations (62) and (63).

From the formulas specified above it follows that the sums of the series terms, which are included in the formulas, are proportional to the common factors of different degrees of value $\left(\frac{H}{B}\right)$. At magnitude of value $\left(\frac{H}{B}\right) \ll 1$ during the approximate calculations it is possible to restrict oneself to not a big number of Fourier series components. At the values of $\beta\left(t_{0}\right)$ of the order of 1 value $B$ could be of the order of $\frac{1}{\sqrt{1-\beta\left(t_{0}\right)^{2}}}$. And that is why parameter $\left(\frac{H}{B}\right)$ could be considered small at high value of external wave intensity. From the above it follows, that smallness of parameter $\left(\frac{H}{B}\right)$ could be used in a very wide range of the wave and electron parameters.

\section{APPROXIMATE SOLUTION OF THE EQUATIONS OF ELECTRON DYNAMICS IN WAVE POLARIZATION PLANE}

For investigation of electron dynamics in polarization plane we should set the value of constant $a$ equal to zero $(a=0)$, and to make the formulas simpler, we will set $\delta=0$.

We will specify the equations for calculation of $\beta_{x 0}, \beta_{z 0}$, received with consideration only of the first harmonic $(n=1)$ and average values $\left(c_{x}, c_{y}\right)$ under the following conditions: in expansion of $\cos \varphi_{s}$ only two terms $\left(\cos \varphi_{s} \approx 1-\frac{\varphi_{s}^{2}}{2}\right)$ were kept, and in expansion of $\sin \phi$ only one term $\left(\sin \varphi_{s} \approx \varphi_{s}\right)$ was kept.

$$
2 c_{x}+2\left(q_{1} \cos \frac{\Phi_{0}}{1+\Lambda_{x}}-r_{1} \sin \frac{\Phi_{0}}{1+\Lambda_{x}}-X\right)=0
$$




$$
2 c_{z}+2\left(Q_{1} \cos \frac{\Phi_{0}}{1+\Lambda_{x}}-R_{1} \sin \frac{\Phi_{0}}{1+\Lambda_{x}}-Z\right)=0
$$

where

$$
\begin{aligned}
& X=\beta \cos \theta \\
& Z=\beta \sin \theta \\
& q_{1}=-\frac{c_{x} \Lambda_{z} H^{3}}{32 B^{3}} \\
& r_{1}=\frac{C H}{2 B^{2}}+\frac{C H^{5}}{512 B^{6}\left(1+\Lambda_{x}\right)^{2}}+\frac{3 C H^{3} \Lambda_{z}^{2}}{16 B^{4}\left(1+\Lambda_{x}\right)^{2}} \\
& Q_{1}=\frac{1}{B}\left(-\frac{C H^{3} \Lambda_{z}}{32 B^{3}\left(1+\Lambda_{x}\right)^{2}}\right) \\
& R_{1}=\frac{1}{B}\left(-\frac{H}{2}+\frac{H^{5}}{512 B^{4}\left(1+\Lambda_{x}\right)^{2}}+\frac{3 H^{3} \Lambda_{z}^{2}}{16 B^{2}\left(1+\Lambda_{x}\right)^{2}}\right)
\end{aligned}
$$

Left parts of equations (69) and (70) are the functions $\beta$ and $\theta$.

Approximate solutions of the equations were found by breaking down equations (69), (70) into series with respect to $\beta$ and $\alpha$, assuming $H \ll 1 ; \beta \ll 1 ; \alpha<1$, where $\theta=\pi-\alpha$. Under the condition that $\theta=\pi-\alpha$ or $\theta=\alpha$, distribution of $\beta$ and $\alpha$ was investigated, depending on the wave and electron parameters, in the direction opposite to the direction of the wave propagation.

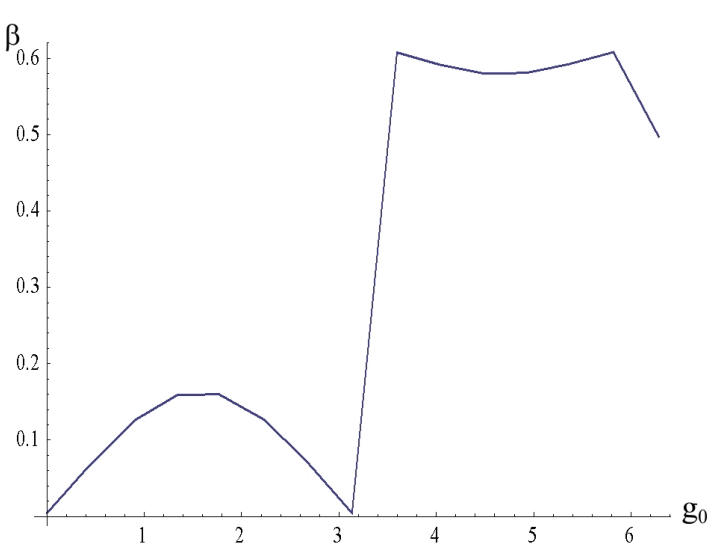

Figure 1. Dependence of initial electron velocity on initial generalized phase value

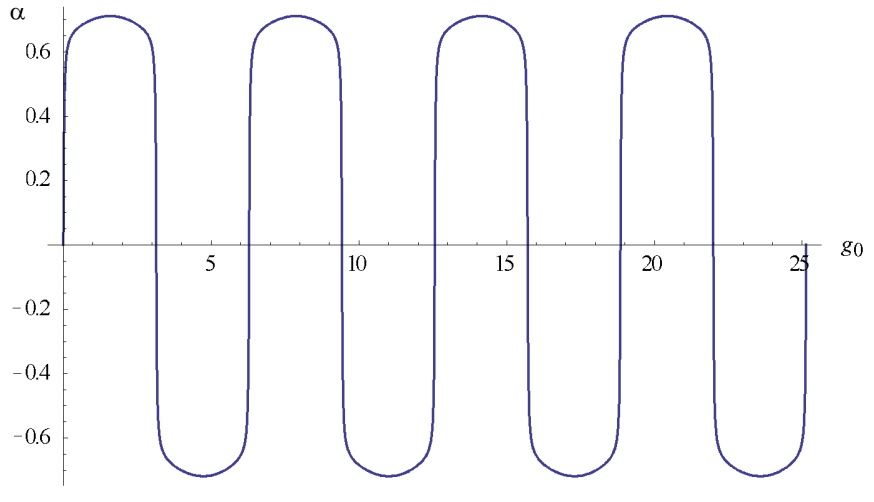

Figure 2. Dependence of electron velocity vector angle to wave reverse direction from generalized phase initial value

Figure 1 presents the dependences of $\beta$ on the value of $g_{0}$, at the initial time moment $t_{0}$, and which pertain to the case of electron moving in the direction opposite to the direction of wave propagation.

On Figure 2 one can see the beginning of two-electron beams formation, deflected from direction $\theta=\pi$. One beam is moving towards $(\pi-\alpha)$, and the other one is moving in the direction $(\pi+\alpha)$. Appearance of the two beams depends on the value of different intervals of $g_{0}$, where the electrons were located at the initial moment of time.

\section{CONCLUSION}

Application of the theory of almost periodic functions made it possible to solve the problem of dynamics of relativistic electron in the field of progressing TEM wave. It made it possible to demonstrate the availability of timeindependent summands in the value of the speed of the electron, which moves in TEM wave. In progressing wave the availability of the electrons moving at high speed in the direction opposite to the direction of the wave propagation was detected. Within the framework of quantum electrodynamics this effect is explained by dispersion of electrons and photons. A very important circumstance is also the fact, that the theory makes it possible to investigate electron dynamics depending on the original wave intensity. 


\section{ORCID IDs}

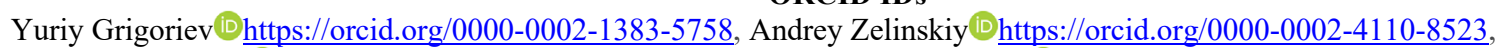

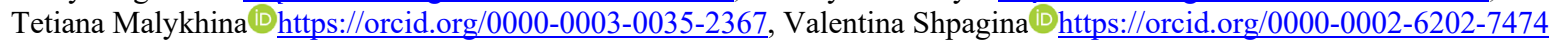

\section{REFERENCES}

[1]. Yu.N. Grigoriev, I.V. Drebot, O.D. Zvonaryova and A.Yu. Zelinsky, VANT, 6, 150-153 (2005).

[2]. G. Bor, Almost periodic functions, (Editorial URSS, Moscow, 2009), 128 p. (in Russian)

[3]. H.A. Avetissian, Relativistic Nonlinear Electrodynamics, (2nd ed.), (Springer International Publishing, Switzerland, 2016) Vol 88, pp. 463-499, doi: 10.1007/978-3-319-26384-7 1.

[4]. U. Rehmann, Encyclopedia of Mathematics, (Springer, 2018), Retrieved from http://www.encyclopediaofmath.org.

[5]. C.F. Muckenhoupt, J. Math. Phys. Massachusetts Inst. Technology, 13(3), 17-22 (1929). 